\title{
INDIVIDUAL AND AGGREGATE STOCK RETURNS IN KOREAN STOCK MARKET
}

\author{
TeWhan Hahn, Auburn University, Montgomery, Alabama, USA
}

dx.doi.org/10.18374/JIBE-13-1.10

\begin{abstract}
Now emerging stock market studies are facing methodological challenges. As Durham (2000) warns, it is highly possible that in emerging stock markets, the fundamentals do not move with returns. In that case, applying investment strategies suggested by U.S. market studies directly in emerging market without checking the fundamental variables' explanatory power of returns can be reckless. Using Korean stock market as an example, we show that, although Fama-French three factor model can explain the aggregate stock return pretty well, there is no consistent fundamental variable in predicting individual stock returns. This indicates that investment timing and the holding period decisions are more important in selecting stocks in emerging stock market than in U.S. or more industrialized countries. Overall the results of this study strongly question the validity of trading strategy based studies which use fundamental variables as sorting variables without checking the significance of the sorting variables in explaining returns.
\end{abstract}

Keywords: Fama-French Three Factor Model, Fundamental Variables. 